\title{
Thermodynamic and kinetic study of adsorptive removal of lead by the nanocomposite loaded nanofibers
}

\author{
Urwa MAHMOOD (D), Sharjeel ABID (D), Bilal QADIR (D), Ahsan NAZIR* (D), Tanveer HUSSAIN(D) \\ Electrospun Materials \& Polymeric Membranes Research Group, National Textile University, Faisalabad, Pakistan
}

\begin{tabular}{|c|c|c|c|}
\hline Received: 31.07 .2021 & $\bullet$ & Accepted/Published Online: 10.11 .2021 & Final Version: 27.04 .2022 \\
\hline
\end{tabular}

\begin{abstract}
Herein, the fabrication of electrospun nanocomposites, using polyacrylonitrile nanofibers (PNF) modified with nanobentonite and fly ash, is explained. Further, the use of electrospun adsorbent for the remediation of $\mathrm{Pb}$ (II) ions from water has been explored. Pristine PNF and nanocomposites were characterized using SEM, EDX, and FTIR to analyze surface topology, elemental composition, and functional groups, respectively. The adsorptive behavior of developed adsorbents was investigated using the effects of dosage, initial concentration, time, and temperature. Pseudo-second order kinetics fit well with experimental data and the adsorption followed intra-particle diffusion. The thermodynamics study confirmed spontaneous endothermic adsorption of the heavy metal. Nanocomposites-based adsorbents showed improved adsorption capacity for $\mathrm{Pb}$ (II) ions compared to pristine PNF.
\end{abstract}

Key words: Electrospun nanofibers, nanocomposites, heavy metals, adsorption, bentonite, fly ash

\section{Introduction}

Hazardous discharge from industries is the primary cause of heavy metal contamination in water, which has gained considerable importance in the last decades. These contaminations are caused by various industrial activities. These activities are the major contributors of heavy metals contamination, including lead, chromium, arsenic, zinc, mercury, cobalt, copper, and others [1]. The effluents from these industries contain a very high concentration of harmful heavy metals, much higher than the limits defined by the World Health Organization (WHO) [2].

Heavy metals are toxic and, in many cases, are carcinogenic towards living beings. Lead, one of the most commonly found toxic metals, has hazardous effects on living beings even at low concentrations [3]. About 5\%-15\% of lead taken up by humans enters the body through the digestive route, while $20 \%-80 \%$ enters through the respiratory tract. Food containing lead ions causes absorption of lead within the body, especially lungs and stomach, enters into the bloodstream, adheres to blood cells, and forms clots in joints and bones. Their intervention with different body organs results in anemia, kidney disorder, liver damage, adverse effects on the reproductive system, mental illness, and in severe cases, cancer in adults. Woefully, it also causes various treacherous effects on children, including abnormal brain development, brain swelling, severe disabilities, dental issues, abnormal behavioral changes, and encephalopathy [4]. These facts suggest the development of water treatment systems to remove lead from wastewater.

Different techniques have been devised for the treatment of heavy metals, including lead from wastewater. These includes ion exchange [5], chemical precipitation [6], coagulation [7], flocculation [8], membrane separation [9], ultrafiltration, and oxidation-reduction process $[10,11]$. However, these techniques offer low removal efficiency, higher operation, and maintenance costs, result in a larger amount of waste, and pollute the ecosystem. Further, they may require secondary treatments in addition to the primary treatments making the process highly expensive. Different approaches have been proposed to overcome these problems and are more efficient and cheaper [12]. Most of these techniques are based on the adsorption process and offer advantages, including cost-effectiveness, flexibility, and high purity of the treated water $[13,14]$. The advantages of the adsorption process can be multiplied using nanomaterials thanks to their exceptional properties, including high surface-to-area ratio, tunable porosity, easy fabrication, and wide range of choices for the surface functionalization [15].

Several researchers explored the potential of different nanomaterials for the lead adsorption. Lai et al. reported a biomass composite having a porous structure incorporated with titanium oxide functionalized graphene oxide for the

*Correspondence: ahsan@ntu.edu.pk 
decontamination of lead in wastewater and showed good absorption (132 mg. $\left.\mathrm{g}^{-1}\right)$. The composite was regeneratable at mild conditions and good thermal stability and had high lead uptake even after several repetition cycles. At the same time, the adsorption was followed by the pseudo-second-order kinetics and Langmuir model [16]. Gebru et al. fabricated cellulose acetate (CA) nanofibers incorporated with titanium oxide $\left(\mathrm{TiO}_{2}\right)$ for the adsorption of $\mathrm{Pb}$ (II) and $\mathrm{Cu}$ (II). As a result of increasing the $\mathrm{TiO}_{2}$ above $2.5 \%$, adsorption efficiency reduces. The reduction in adsorption efficiency was due to the agglomeration, which decreases porosity and surface area [17]. Li et al. developed electrospun PAN nanofibers loaded with $\mathrm{MnO}_{2}$ using polydopamine coating to capture $\mathrm{Pb}$ (II) ions. The adsorption capacity of the adsorbent was $185 \mathrm{mg} \cdot \mathrm{g}^{-1}$ as calculated by Langmuir isotherm [18].

Electrospun nanomaterials $t$ can immobilize heavy metal impurities, including lead using adsorption process [19, 20]. Especially, the capability of electrospun materials to be functionalized allows them to act as adsorbent materials for the immobilization of lead ions. Additionally, these materials offer several advantages, including low manufacturing and operating costs, effortless operation, low energy consumption, ease of maintenance, and lower carbon footprint [21]. Numerous approaches have been used to improve the properties of electrospun nanomaterials compared to conventional materials. These include modifications, a combination of polymers or additives, surface coatings, functionalized additives, and polymers [22]. Especially the electrospun nanomaterials developed using polymeric adsorbents modified with different additives have drawn considerable attention for wastewater treatment. For example, researchers have fabricated composite nanofibers containing polycaprolactone impregnated with clay and zeolite having a synergistic effect on the adsorption capacity of $\mathrm{Pb}$ (II). The results showed that adsorption was a spontaneous process and observed the Freundlich model and pseudo-second order kinetics [23]. Similarly, Thamer et al. improved the adsorption of $\mathrm{Pb}$ (II) using carbon nanofibers (CNFs) functionalized with poly(m-phenylene diamine) and melamine. The poly(m-phenylene diamine) based materials showed spontaneous and endothermic adsorption while the melamine functionalized sample materials exothermic adsorption [24].

Researchers have used different polymers to develop electrospun nanomaterials for heavy metal adsorption from wastewater, for example, polyamide 6 (PA6), polyvinylidene fluoride (PVDF), and others. Among these materials, polyacrylonitrile (PAN) is considered one of the most suitable candidates for electrospinning thanks to its low cost and exceptional chemical, thermal and mechanical stability; however, its adsorption properties can be improved further towards heavy metals [25]. To improve the $\mathrm{Pb}$ (II) adsorption of electrospun PNF, the current study employed a composite of Smectites (bentonite) and fly ash that was expected to work synergistically to enhance lead adsorption. Bentonite possesses a higher cation exchangeability for heavy metals and is readily available at a low cost [12]. Similarly, fly ash, a waste material of various industrial activities, is known to provide adsorption sites to remove $\mathrm{Pb}$ (II) [26]. A nanocomposite consisting of PAN, bentonite, and fly ash was produced and cross-linked to improve the adsorption properties. The developed nanocomposites were evaluated for lead adsorption at different doses, contact time, and temperatures. Further, adsorption kinetics, isotherms, and thermodynamics parameters of the developed nanocomposites were studied.

\section{Experimentation details}

\subsection{Materials}

Polyacrylonitrile (PAN, analytical grade, molecular weight (MW) $150,000 \mathrm{~g} / \mathrm{mol}$ and density $(\rho) 1.184 \mathrm{~kg} / \mathrm{cm}^{3}$ ) was procured from Exlan Corp, Japan, while dimethylformamide (DMF, GR grade, purity $99.5 \%$ and $\rho 0.0944 \mathrm{~kg} / \mathrm{cm}^{3}$ ) were obtained from Sigma Aldrich Germany. Bentonite Clay was purchased from DAEJUNG chemicals, Korea, and fly ash was collected from Sitara Chemicals, Pakistan. Lead Nitrate (purity 99.0\% \& MW 331.21) were obtained from Sigma Aldrich Germany. Epichlorohydrin (GR grade, purity 99.0\%) was procured from DUKSAN reagents, Korea.

\subsection{Fabrication of mixed matrix membranes}

\subsubsection{Development of nanocomposites}

Bentonite and fly ash were blended with different bentonite to fly ash ratios of 80:20, 40:60, 60:40, and 20:80 using a mortar piston. The blended samples were then calcinated in a quartz tube furnace (PT-1200T, Zhengzhou Protech Technology Co., Ltd. China) at a ramp of $10{ }^{\circ} \mathrm{C} / \mathrm{min}$ up to $700{ }^{\circ} \mathrm{C}$ and kept at $700{ }^{\circ} \mathrm{C}$ for $300 \mathrm{~min}$.

\subsubsection{Fabrication of PAN nanofibers}

To prepare 8\% (wt/v) PAN dope solution, the required amount of PAN precursor was dissolved in $60 \mathrm{~mL}$ of DMF followed by vigorous stirring for $12 \mathrm{~h}$. The homogenized solution was then subjected to Nanospider electrospinning (ELMARCO, Czech Republic) with varying parameters. Nanofibers were optimized to a minimum diameter which reduces the fiber-tofiber diameter and increases the contact time of adsorbents with $\mathrm{Pb}$ (II) ions. After the preliminary trials, the minimum diameter of nanofibers was achieved at the following parameters carriage speed of $80 \mathrm{~mm} / \mathrm{s}$. The distance between the 
spinning electrode and substrate was $200 \mathrm{~mm}$ with $30 \mathrm{kV}$ voltage. A schematic diagram of electrospinning is shown below in Figure 1. Electrospun webs were collected on an aluminum file and placed in an oven at $60^{\circ} \mathrm{C}$ for $5 \mathrm{~h}$ to evaporate the solvent and then peeled off from an aluminum file. All the electrospun webs were stored in an airtight container to prevent external contamination and future use.

\subsubsection{Crosslinking of PAN}

The pristine PAN nanofibers were treated with $2.5 \%$ epichlorohydrin $(\mathrm{ECH})$ solution to cross-link and coated with bentonite fly ash nanocomposites then subjected to drying in an oven (Thermo Fisher Scientific, United States) at $60{ }^{\circ} \mathrm{C}$. The developed adsorbents with compositions 80:20, 40:60, 60:40, and 20:80 are NC1, NC2, NC3, and NC4, respectively.

\subsection{Material characterizations}

\subsubsection{Scanning electron microscopy (SEM)}

Adsorbents were placed on stubs using conductive adhesive tape and gold-coated for $30 \mathrm{~s}$ using a sputter coater (Desk V). SEM (Nova, nanoSEM 450, FEI Czech Republic) with secondary electron detector mode was used at $10 \mathrm{kV}$ for the fabricated adsorbents' morphological and surface textural analysis.

\subsubsection{Energy dispersive $\mathrm{x}$-ray spectroscopy (EDX)}

For the elemental analysis of developed adsorbents, EDX (Oxford INCA X'Act) was used.

\subsubsection{Fourier transform infrared spectroscopy (FTIR)}

Pristine PAN nanofibers and nano impregnated adsorbents were analyzed on FTIR (ZnSe-HATR Module, Perkin ElmerSpectrum two, USA) with an average of 20 scans in the scanning range of 4000-600 $\mathrm{cm}^{-1}$ and resolution of $4 \mathrm{~cm}^{-1}$ for the identification of chemical structure.

\subsubsection{Batch adsorption studies}

Batch adsorption studies was used to analyze the adsorption capacity of developed adsorbents. A stock solution of $\mathrm{Pb}$ (II) of $100 \mathrm{ppm}$ was prepared using $1 \%$ nitric acid and lead nitrate salt to optimize the dosage of adsorbents at $20^{\circ} \mathrm{C}$ temperature for $8 \mathrm{~h}$. Further, the effect of time and temperature on the adsorption was studied. After the adsorption, adsorbate was filtered and diluted prior to ICP analysis (ICP-OES 5110, Agilent, USA). The adsorption kinetics was performed under the optimized conditions while the thermodynamics of the adsorption process were investigated from $20{ }^{\circ} \mathrm{C}$ to $45{ }^{\circ} \mathrm{C}$. After adsorption experimentations, lead concentrations were determined using ICP analysis at a wavelength of 220.353 $\mathrm{nm}$ [27]. Calibration solutions of $0.25 \mathrm{ppm}, 0.5 \mathrm{ppm}, 1 \mathrm{ppm}, 1.5 \mathrm{ppm}$, and $2 \mathrm{ppm}$ were prepared using $1 \%$ nitric acid and lead nitrate salt.

The adsorbed amount of $\mathrm{Pb}$ (II) and adsorption efficiency (\%) of adsorbents were calculated using the following relations [28].

$$
\begin{array}{lr}
q_{t}=\left(C_{0}-C_{e}\right) V / M & \text { Equation } 1 \\
\text { Removal efficiency }(\%)=\left(C_{0}-C_{e}\right) / C_{0} \times 100 & \text { Equation 2 }
\end{array}
$$

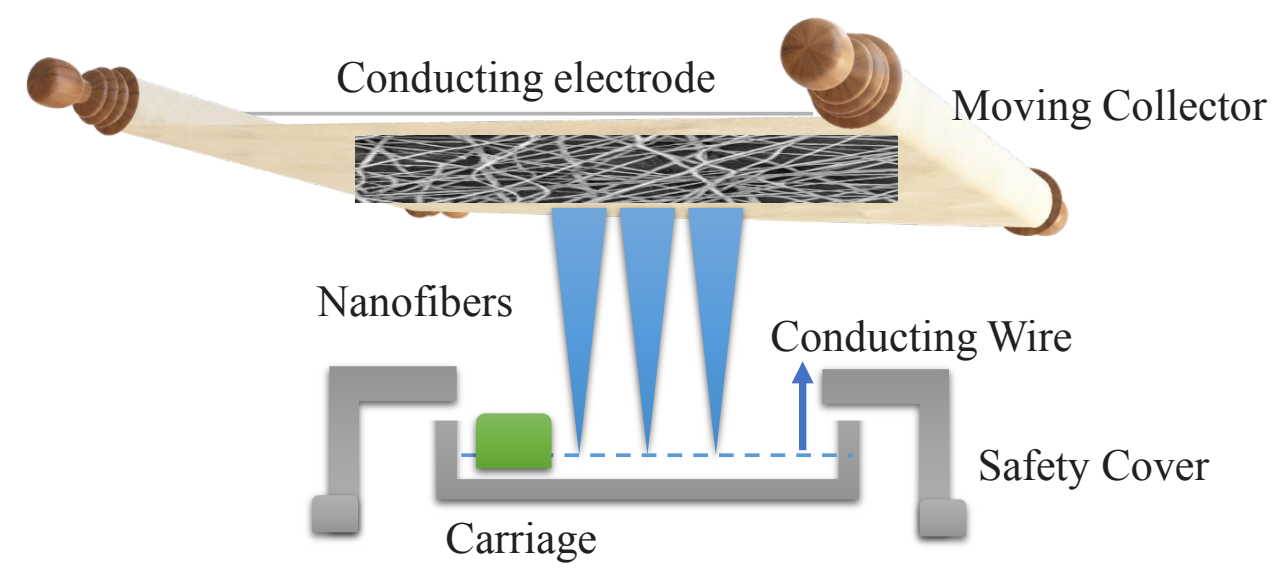

Figure 1. Needleless electrospinning process. 
Where $V$ is the volume of solution in liters (L), $M$ is the weight of adsorbent in grams $(\mathrm{g}), q_{t}$ is the adsorbate amount adsorbed per unit time, $C_{0}$ and $C_{e}$ are the initial and equilibrium concentrations in $\mathrm{mg}$ per $\mathrm{g}\left(\mathrm{mg} \cdot \mathrm{g}^{-1}\right)$, respectively.

\subsubsection{Thermodynamics}

Thermodynamics analysis provides the information about the adsorption behavior and the parameters of thermodynamics include Activation entropy $\left(\Delta S^{\prime}\right)$, enthalpy $\left(\Delta H^{\prime}\right)$, and Gibbs free energy $\left(\Delta \mathrm{G}^{\prime}\right)$ and can be calculated in following relations [29].

$$
\begin{aligned}
& K_{e}={ }^{q_{e}} / C_{e q} \\
& \Delta G^{\prime}=-R \cdot T \cdot \ln K_{e} \\
& \Delta G^{\prime}=\Delta H^{\prime}-T \cdot \Delta S^{\prime} \\
& \ln K_{e}=\Delta S^{\prime} /_{R}-\Delta H^{\prime} /_{R T}
\end{aligned}
$$

Equation 3

Equation 4

Equation 5

Equation 6

Here, $q_{e}\left(\mathrm{mg} \cdot \mathrm{g}^{-1}\right)$ is the adsorbed concentration at equilibrium, $C_{e q}\left(\mathrm{mg} \cdot \mathrm{g}^{-1}\right)$ is the equilibrium concentration, $R$ (K.J.mol ${ }^{-}$ $\left.{ }^{1} \cdot \mathrm{K}^{-1}\right)$ is considered as ideal gas constant, $\mathrm{T}(\mathrm{K})$ and $K_{e}$ are absolute temperature and equilibrium constant, respectively. The $\Delta \mathrm{G}^{\prime}$ and $\Delta \mathrm{H}^{\prime}$ values can be estimated by plotting a linear curve of Van't Haff plot (ln $K_{e} \mathrm{vs} 1 / \mathrm{T}$ ) [30]. However, the equilibrium constant $\left(K_{e}\right)$ can be calculated using the Equation 3.

\subsubsection{Adsorption kinetics}

Kinetic models have been proposed to determine the mechanism of the adsorption process that provides valuable data such as reaction pathways to improve the efficiency and feasibility for the scale-up of the adsorption process [31,33]. To serve this purpose, five different kinetic models, i.e. pseudo-first order model, pseudo-second order model, Elovich model, Bangham's model, and intra-particle diffusion model, were employed on the experimental equilibrium adsorption data. All the models were applied in their linearized forms.

The pseudo-first order model was employed on the dynamic data to estimate the rate of $\mathrm{Pb}$ (II) adsorption rate on pristine PNF, NC1, NC2, NC3, and NC4. This model provides key information about the diffusion of adsorbate through the adsorbent interface. The linear form of the pseudo-first order kinetic model is given in Equation 7 [34].

$$
\ln \left(q_{e}-q_{t}\right)=\ln q_{e}-k_{1} t
$$

whereas, $q_{e}\left(\mathrm{mg} \cdot \mathrm{g}^{-1}\right), q_{t}\left(\mathrm{mg} \cdot \mathrm{g}^{-1}\right)$ are the adsorption capacity at equilibrium and at a time $(\mathrm{t}), k_{1}\left(\mathrm{~min}^{-1}\right)$ is the pseudo-first order constant and can be estimated by plotting t vs. $\ln \left(q_{e}-q_{t}\right)$. To understand the kinetics of $\mathrm{Pb}$ (II) adsorption on pristine and NF composite, pseudo-second order model was applied linearly on equilibrium adsorption data using the following expression [35].

$$
\frac{t}{q_{t}}=\frac{1}{k_{1} q_{e}^{2}}+\frac{t}{q_{e}}
$$

Equation 8

Where $q_{t}\left(\mathrm{mg} \cdot \mathrm{g}^{-1}\right)$ and $q_{e}\left(\mathrm{mg} \cdot \mathrm{g}^{-1}\right)$ are the instantaneous and equilibrium adsorption capacity of nanocomposites and $k_{1}\left(\mathrm{~g} \cdot \mathrm{mg}^{-1} \cdot \mathrm{min}\right)$ is the constant associated with the pseudo-second order model.

Bangham model was applied on the equilibrium adsorption data to evaluate adsorption mechanisms such as pore diffusion. The linear form of the Bangham's model is represented as follow [36]:

$$
\log \left(\frac{C_{i}}{C_{i}-q_{t} M}\right)=\log \left(\frac{k_{1}}{2.303 V}\right)+\beta \log t
$$

Where $C_{i}\left(\mathrm{mg} . \mathrm{L}^{-1}\right)$ is the initial concentration of $\mathrm{Pb}$ (II) ions in the solution, and $\mathrm{M}(\mathrm{g})$ is the mass of adsorbent, $\mathrm{V}(\mathrm{L})$ is the volume of solution whereas, $\beta$ is the constant of the Bingham model. Similarly, intra-particle diffusion (Weber and Morris) was employed to distinguish various diffusion mechanisms to identify the dominant rate-limiting step for $\mathrm{Pb}$ (II) adsorption on new PNF, NC1, NC2, NC3, and NC4. The intra-particle diffusion model can be represented as [36].

$$
q_{t}=k_{1} \sqrt{t}+B_{1}
$$

Where, $k_{1}\left(\mathrm{mg} \cdot \mathrm{g}^{-1} \cdot \mathrm{min}^{1 / 2}\right)$ the constant of the model and $B_{1}\left(\mathrm{mg} \cdot \mathrm{g}^{-1}\right)$ is the thickness of the boundary layer. The large value of $B_{1}$ implies that the boundary layer has a prominent influence on the $\mathrm{Pb}$ (II) ion adsorption. 


\section{Results and discussion}

\subsection{FTIR}

FTIR spectra of pristine PNF, NC1, NC2, NC3, and NC4 are shown in Figure 2. In the FTIR spectra of pristine PNF, the broad transmittance peak at $3434 \mathrm{~cm}^{-1}$ indicates the $-\mathrm{OH}$ stretching due to absorbed moisture from the atmosphere. The transmittance peak at $2854 \mathrm{~cm}^{-1}$ and $2920 \mathrm{~cm}^{-1}$ corresponds to symmetric and asymmetric -C-H stretching [37]. The characteristic peak at $2244 \mathrm{~cm}^{-1}$ is ascribed to the vibrational stretching of $-\mathrm{C} \equiv \mathrm{N}$, and sharp peaks at 1731 and $1448 \mathrm{~cm}^{-1}$ correspond to the vibrational stretching of $-\mathrm{C}=\mathrm{O}$ and $-\mathrm{C}-\mathrm{H}$ respectively $[38,39]$. The peak at $1665 \mathrm{~cm}^{-1}$ is assigned to $-\mathrm{C}=\mathrm{C}$ stretching, which disappears in the spectra of cross-linked nanofibers [40]. The peak of strong $-\mathrm{CH}_{2}$ stretching is observed at $1076 \mathrm{~cm}^{-1}$ [41]. However, after the cross-linking of PNF with ECH, some significant changes have been observed in the

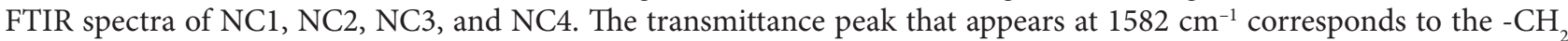
vibrations due to the cross-linking of pristine PNF with ECH [42]. Further, the spectrum of NC1, NC2, NC3, and NC4 conforms to the absorption band at $1044 \mathrm{~cm}^{-1}$ attributed to stretching vibrations of $\mathrm{Si}-\mathrm{O}, \mathrm{SiO}-\mathrm{SiO}$, and $\mathrm{Si}-\mathrm{Si}$ groups [43, 44]. The FTIR analysis confirms the successful cross-linking of PNF without modifying the surface functionalities.

\subsection{Surface topology (SEM analysis)}

The topological highlights of PNF, NC1, NC2, NC3, and NC4 are shown in Figures 3 (a)-3(e), respectively. The micrograph of PNF (Figure 3 a) exhibits the smooth, nonporous surface and bead-free structure of nanofibers. However, after the loading of nanocomposite on nanofibers, agglomeration can be observed in the micrographs of NC1, NC2, NC3, and NC4, as shown in Figures 3 (b)-3 (e), respectively. It was concluded by scanning electron microscopic analysis that there was a successful loading of NC on nanofibers, as can be seen in Figure 3. The diameter of the PNF and NC was analyzed by using Image J (1.53 e) software. The diameter of PNFs and NCs is summarized in Table 1.

\subsection{Energy dispersive X-ray (EDX)}

The EDX analysis of nanocomposite-based adsorbents is summarized in Table 2. In PNF, no traces of any metallic impurities have been observed. However, with the addition of nanocomposite (Flyah-Bentonite), metallic constituents of

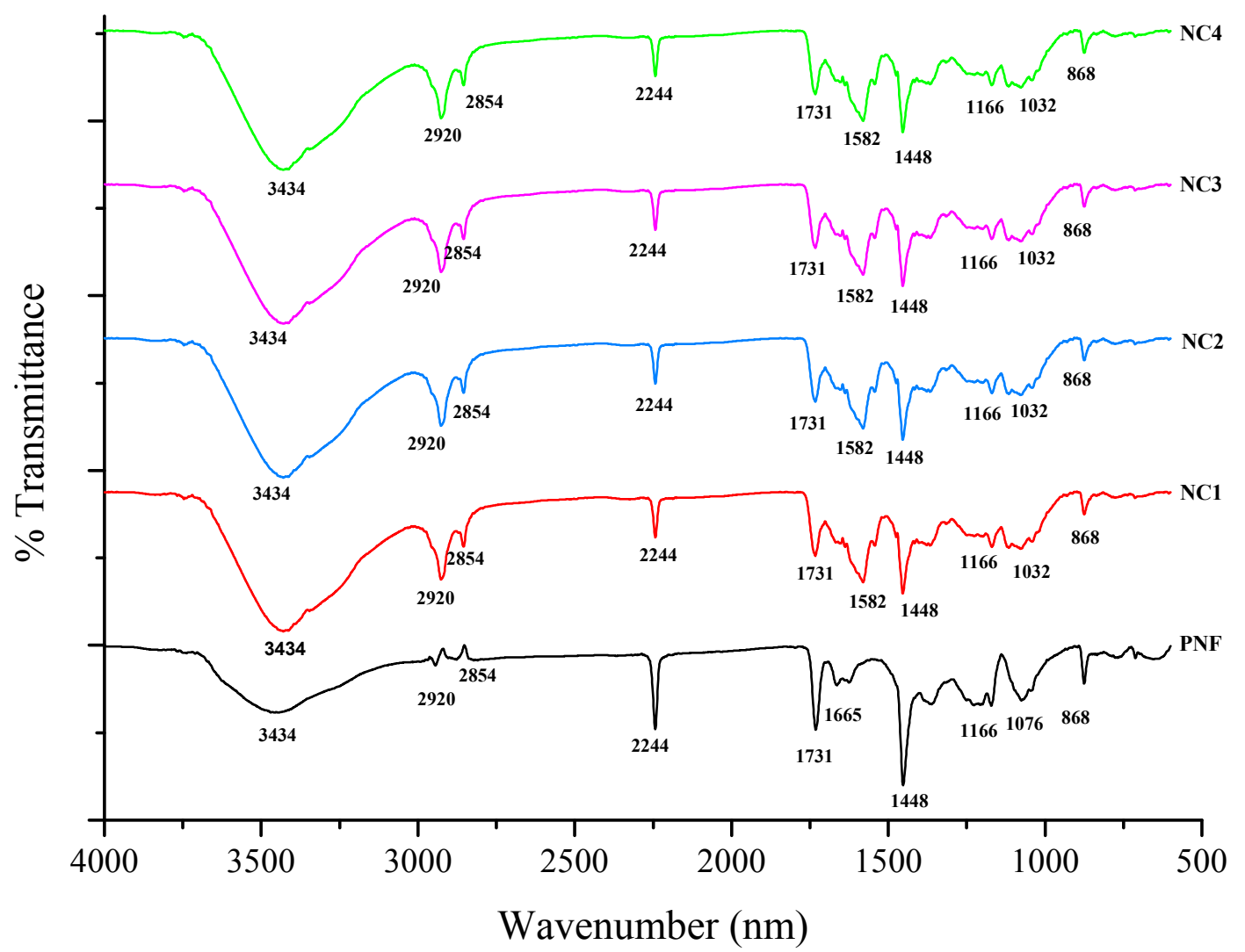

Figure 2. FTIR spectra of developed samples. 

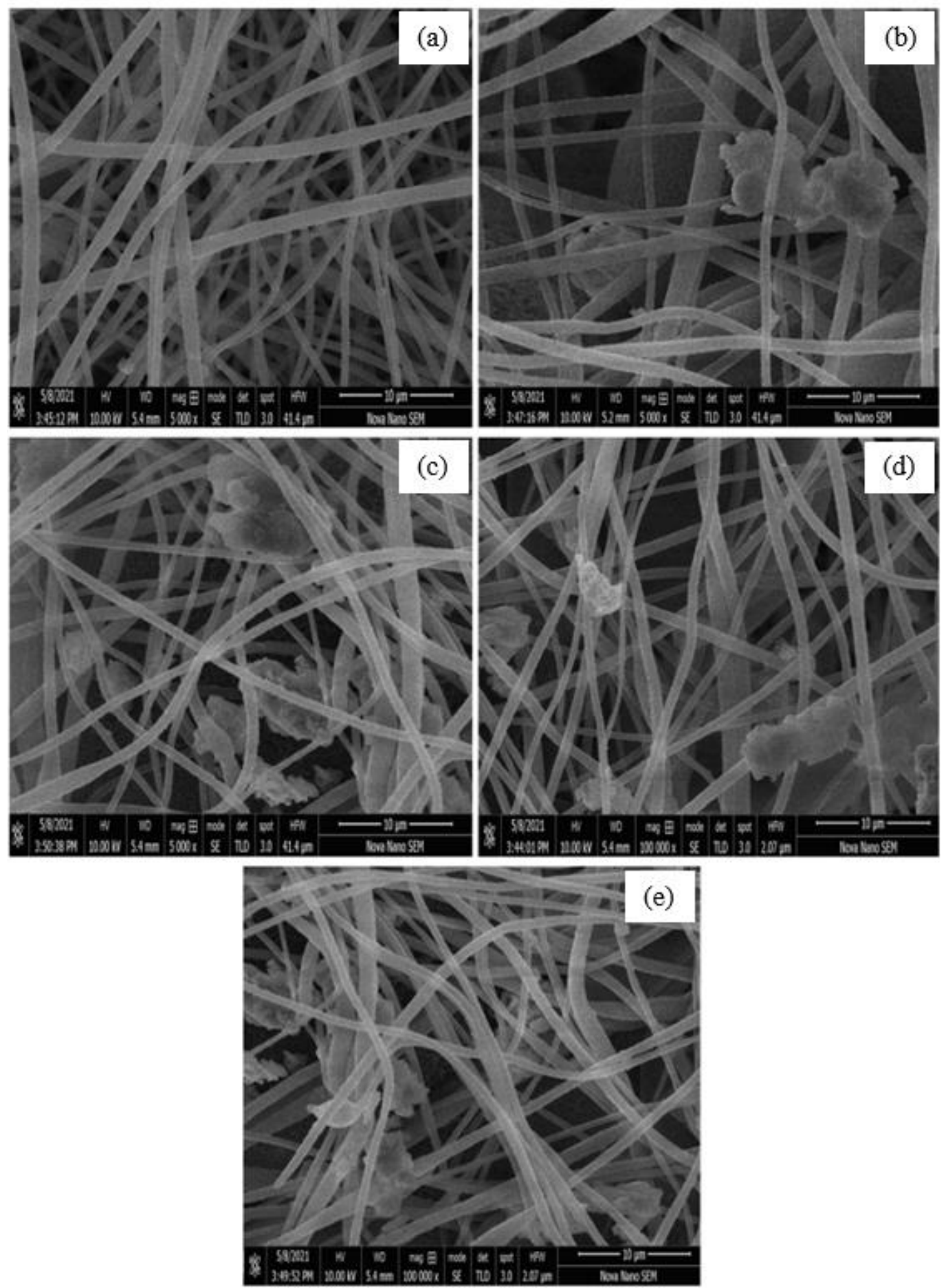

Figure 3. SEM micrographs of (a) pristine PNF, (b) NC1, (c) NC2, (d) NC3, (e) NC4.

nanocomposite are observed, as evident from Table 2. The presence of these metallic constituents in NC1, NC2, NC3, and $\mathrm{NC} 4$ confirmed the successful incorporation of nanocomposite in the electrospun nanofibers.

\subsection{Effect of dosage}

The dosage of adsorbent has a prominent effect on the adsorption capacity of $\mathrm{Pb}$ (II) ions and is demonstrated in Figure 4 . In the case of PNF, the percentage removal remains constant at about $3 \%$ even after increasing the dosage due to the less 
MAHMOOD et al. / Turk J Chem

Table 1. Diameter of adsorbents.

\begin{tabular}{|l|l|}
\hline Adsorbents & Average Diameter $(\mathrm{nm})$ \\
\hline PNF & 113 \\
\hline NC1 & 116 \\
\hline NC2 & 110 \\
\hline NC3 & 112 \\
\hline NC4 & 119 \\
\hline
\end{tabular}

Table 2. Composition of elements in PNF and nanocomposite (NC) samples.

\begin{tabular}{|c|c|c|}
\hline Adsorbents & Element & Weight $\%$ \\
\hline \multirow{3}{*}{ PNF } & Carbon (C) & $91.19 \%$ \\
\hline & Oxygen $(\mathrm{O})$ & $4.78 \%$ \\
\hline & Gold (Au) & $4.03 \%$ \\
\hline \multirow{6}{*}{ NC1 } & Carbon (C) & $54.79 \%$ \\
\hline & Oxygen (O) & $28.08 \%$ \\
\hline & Silicone (Si) & $7.84 \%$ \\
\hline & Aluminum $(\mathrm{Al})$ & $4.26 \%$ \\
\hline & Calcium (Ca) & $1.3 \%$ \\
\hline & Gold (Au) & $3.72 \%$ \\
\hline \multirow{7}{*}{ NC2 } & Carbon (C) & $57.6 \%$ \\
\hline & Oxygen (O) & $21.44 \%$ \\
\hline & Silicone (Si) & $9.41 \%$ \\
\hline & Aluminum $(\mathrm{Al})$ & $5.46 \%$ \\
\hline & Calcium (Ca) & $1.05 \%$ \\
\hline & Iron $(\mathrm{Fe})$ & $1.33 \%$ \\
\hline & Gold (Au) & $3.79 \%$ \\
\hline \multirow{7}{*}{ NC3 } & Carbon (C) & $58.09 \%$ \\
\hline & Oxygen $(\mathrm{O})$ & $17.43 \%$ \\
\hline & Silicone (Si) & $10.54 \%$ \\
\hline & Aluminum $(\mathrm{Al})$ & $7.75 \%$ \\
\hline & Calcium (Ca) & $1 \%$ \\
\hline & Iron $(\mathrm{Fe})$ & $1.37 \%$ \\
\hline & Gold (Au) & $3.81 \%$ \\
\hline \multirow{7}{*}{ NC4 } & Carbon (C) & $59.74 \%$ \\
\hline & Oxygen $(\mathrm{O})$ & $15.04 \%$ \\
\hline & Silicone (Si) & $10.99 \%$ \\
\hline & Aluminum $(\mathrm{Al})$ & $7.99 \%$ \\
\hline & Calcium (Ca) & $0.98 \%$ \\
\hline & Iron $(\mathrm{Fe})$ & $1.41 \%$ \\
\hline & Gold (Au) & $3.85 \%$ \\
\hline
\end{tabular}




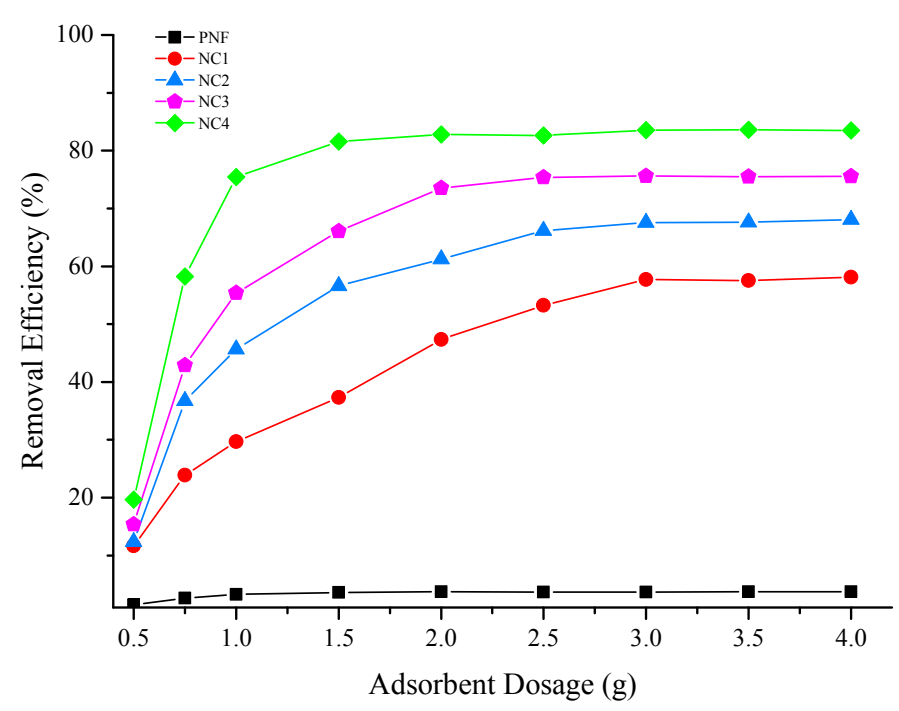

Figure 4. Effect of dosage on the adsorption of $\mathrm{Pb}$ (II) ions.

number of active sites [45,46]. However, the percentage removal of NC1, NC2, NC3, and NC4 increases considerably with the increase in adsorbent dosage owing to the availability of vulnerable sites for adsorption [47]. NC4 showed up to $76 \%$ efficiency, at a dosage of $1 \mathrm{~g}$ as compared to PNF, NC1, NC2, and NC3, adsorbents owing to the availability of active sites. Further increasing the dosage showed no significant improvement in the $\mathrm{Pb}$ (II) adsorption [48,49]. Hence, the dosage of $1 \mathrm{~g}$ nanocomposites was selected for further studies as the maximum efficiency was achieved at $1 \mathrm{~g}$ after increasing the dosage above $1 \mathrm{~g}$, adsorption becomes stagnant with a little change as observed in the Figure 4.

\subsection{Adsorption kinetics}

The adsorption kinetics were studied by varying the contact time from 10 to $420 \mathrm{~min}$. After each time interval, the adsorbate was filtered and analyzed to measure the adsorption capacity. The equilibrium adsorption time for PNF was 20 min, as shown in Figure 5 (a) . No considerable $\mathrm{Pb}$ (II) adsorption was observed after the equilibrium time, which may be due to the occupation of all the active sites for the adsorption [49]. However, the equilibrium adsorption time was increased by incorporating the nanocomposite, as shown in Figure 5 (a). Furthermore, the NC4 exhibits the highest equilibrium adsorption time compared to its counterparts which may be ascribed to the highest fly ash concentration in the incorporated nanocomposite, which offers additional susceptible adsorption sites [50]. Addition of nanocomposite increases the available active sites, therefore, more time was required to establish the adsorption equilibrium state [51, 52]. Hence, the adsorption of NC was remarkably enhanced compared to pristine PNF due to bentonite and fly ash composite.

The parametric values of kinetic models have been summarized in Table 3 and the graphical representations are shown in Figures 5(b)-5(e). The modeled data exhibited that the Pseudo-first order model did not comply well with the equilibrium adsorption data, i.e. $\mathrm{R}^{2}<0.9$ for PNF, NC1, NC2, NC3, and $\mathrm{NC} 4$ as shown in Figure 5 (b). The regression coefficient of the pseudo-second order model $\left(\mathrm{R}^{2}=0.99\right)$ for PNF, NC1, NC2, NC3, and NC4 depicts a good agreement of modeled data with the equilibrium adsorption data compared to its counterparts, as presented in Figure 5 (c). The compliance of the pseudo-second order model revealed that the rate-limiting step for the adsorption of $\mathrm{Pb}$ (II) ions might be the chemisorption which involves electrostatic interactions, including exchangeability of electrons between the $\mathrm{Pb}$ (II) ions and adsorbents [53,54]. Moreover, the Bangham's model did not find an excellent fitting with the dynamic data, as can be seen in Figure 5 (e), which confirms that the $\mathrm{Pb}$ (II) adsorption was not controlled by the pore diffusion mechanism [55]. The plot of the intra-particle diffusion model showed two linear plots, as shown in Figure 5 (f), which demonstrates that there are more than two steps involved in the adsorption of $\mathrm{Pb}$ (II). Moreover, the nonzero intercept of the first linear plot suggested that the adsorption process was diffusion based. Furthermore, the first step indicates the rapid diffusion of $\mathrm{Pb}$ (II) at external layers. In contrast, the gradual adsorption was noticed in the second step where the interparticle diffusion was the rate-limiting step [56,57]. It shows a complicated mechanism owing to the internal diffusion between particles and mass transfer. The deviation of the line from the origin indicates curves deviate from the origin, which means the adsorption process is not only monitored by the diffusion process. Other factors may also affect the adsorption process [2]. Various studies were reported relating to the discussed kinetic models [58, 59]. 

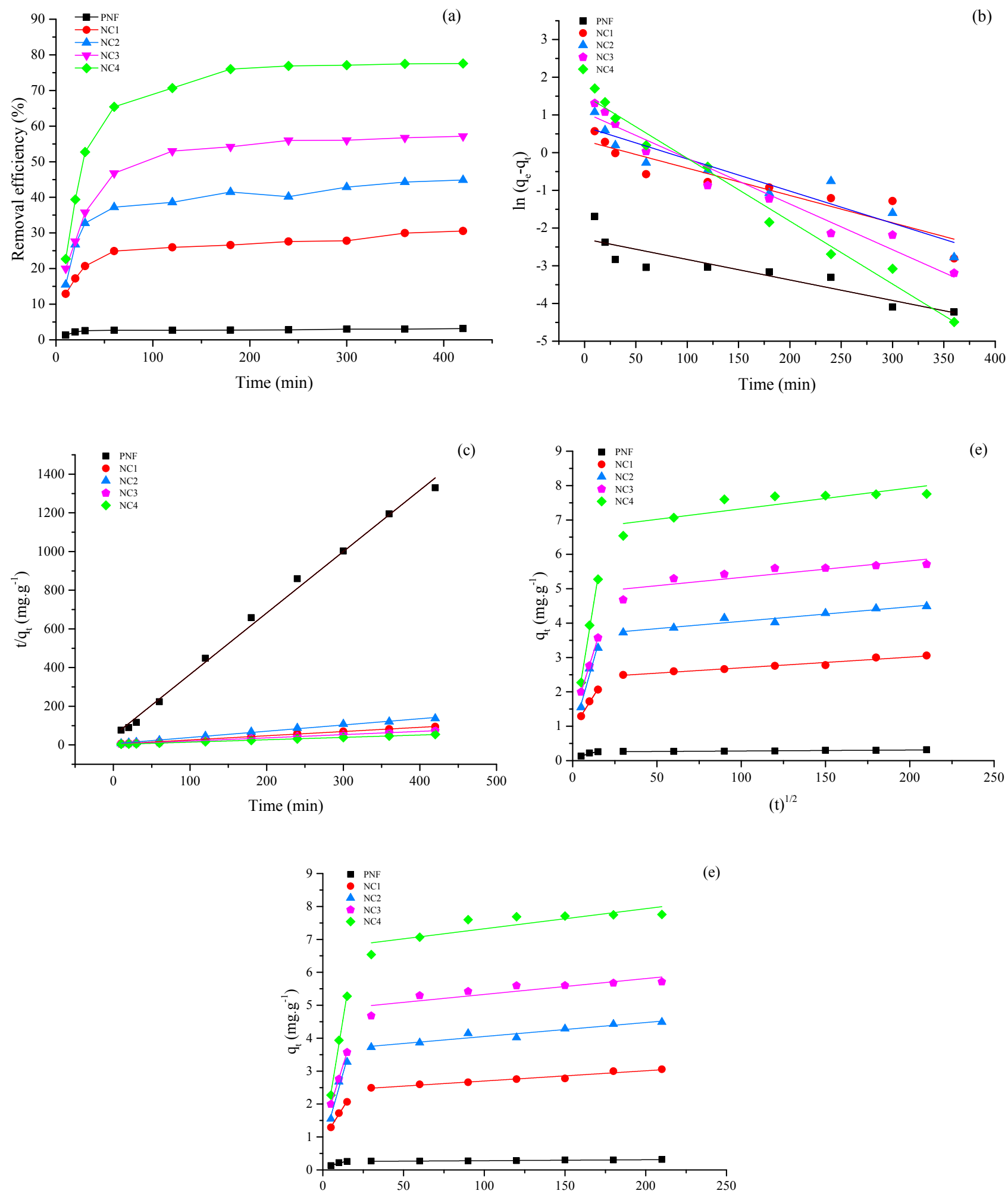

$(\mathrm{t})^{1 / 2}$

Figure 5. Effect of time and kinetic models' plots on the adsorption of $\mathrm{Pb}$ (II) ions using pristine PNF and different nanocomposites (NC) (a) effect of time up to $420 \mathrm{~min}$ at $25^{\circ} \mathrm{C}$ with a dose of $1 \mathrm{~g}$ and initial concentration of $100 \mathrm{ppm}$ at $\mathrm{pH} 6$ (b) pseudo-first order model (c) pseudo-second order model (d) Bangham model (e) intra-particle diffusion model. 


\subsection{Thermodynamics study of adsorption}

The $\mathrm{Pb}$ (II) ions adsorption was examined at temperatures, i.e. $20,25,30,35,40$, and $45^{\circ} \mathrm{C}$, as shown in Figure 6 (a). As evident from Figure 6 (a), the removal of $\mathrm{Pb}$ (II) increases significantly with the rise in solution temperature. This increase in percentage adsorption is associated with the higher kinetic energy of the $\mathrm{Pb}$ (II), which facilitates the adsorption process at higher temperatures $[60,61]$. The $\mathrm{Pb}$ (II) dehydration is increased at high temperatures, which means the process absorbs heat. Dehydration of $\mathrm{Pb}$ (II) ions increases which ultimately facilitates the adsorption [62]. Elevated temperature increases the movement of $\mathrm{Pb}$ (II) ions; thus, more kinetic energy is acquired because of the increase in velocity [63].

The parameters of thermodynamics for $\mathrm{Pb}$ (II) adsorption are mentioned in Table 4 and the Van't Hoff plot is represented in Figure $6(\mathrm{~b})$. The $\Delta \mathrm{G}^{\prime}$ values for pristine PNF over the entire temperature range are positive, which means the adsorption was nonspontaneous. It can be observed that $\Delta \mathrm{G}^{\prime}$ of NC1, NC2, NC3, and $\mathrm{NC} 4$ have negative values at all temperatures that indicate the reaction's spontaneity. However, values of $\Delta \mathrm{G}^{\prime}$ were decreasing as the temperature elevates, which exhibits

Table 3. Kinetic modelling parameters of $\mathrm{Pb}$ (II) adsorption on electrospun PAN and cross-linked composites.

\begin{tabular}{|c|c|c|c|c|c|c|}
\hline \multirow{2}{*}{ Kinetic Models } & \multirow{2}{*}{ Parameters } & \multicolumn{5}{|c|}{ Adsorbents } \\
\hline & & PNF & $\mathrm{NC} 1$ & NC2 & NC3 & NC4 \\
\hline \multirow{3}{*}{ Pseudo-first order } & $\mathrm{q}_{\mathrm{e}}$ & 0.10 & 1.99 & 1.37 & 2.90 & 4.58 \\
\hline & $\mathrm{K}$ & 0.005 & 0.009 & 0.007 & 0.01 & 0.02 \\
\hline & $\mathrm{R}^{2}$ & 0.82 & 0.86 & 0.87 & 0.89 & 0.89 \\
\hline \multirow{3}{*}{$\begin{array}{l}\text { Pseudo-second } \\
\text { order }\end{array}$} & $\mathrm{q}_{\mathrm{e}}$ & 0.315 & 4.59 & 3.09 & 5.99 & 8.17 \\
\hline & $\mathrm{K}$ & 0.00045 & 0.47 & 0.105 & 0.03 & 0.015 \\
\hline & $\mathrm{R}^{2}$ & 0.99 & 0.99 & 0.99 & 0.99 & 0.99 \\
\hline \multirow{3}{*}{ Bangham's } & $\mathrm{K}$ & 0.40 & 1.12 & 0.98 & 1.13 & 1.24 \\
\hline & $\beta$ & 14.25 & 10.36 & 11.59 & 8.76 & 8.22 \\
\hline & $\mathrm{R}^{2}$ & 0.71 & 0.80 & 0.91 & 0.89 & 0.83 \\
\hline \multirow{5}{*}{$\begin{array}{l}\text { Intra- particle } \\
\text { diffusion }\end{array}$} & $\mathrm{B}_{1}$ & 0.08 & 0.77 & 0.91 & 1.69 & 3.21 \\
\hline & $\mathrm{K}_{1}$ & 0.01 & 0.17 & 0.08 & 0.104 & 0.08 \\
\hline & $\mathrm{R}^{2}$ & 0.93 & 0.97 & 0.99 & 0.96 & 0.73 \\
\hline & $\mathrm{B}_{2}$ & 0.25 & 3.63 & 2.39 & 5.18 & 7.51 \\
\hline & $\mathrm{K}_{2}$ & 0.0003 & 0.0042 & 0.0031 & 0.003 & 0.0012 \\
\hline
\end{tabular}
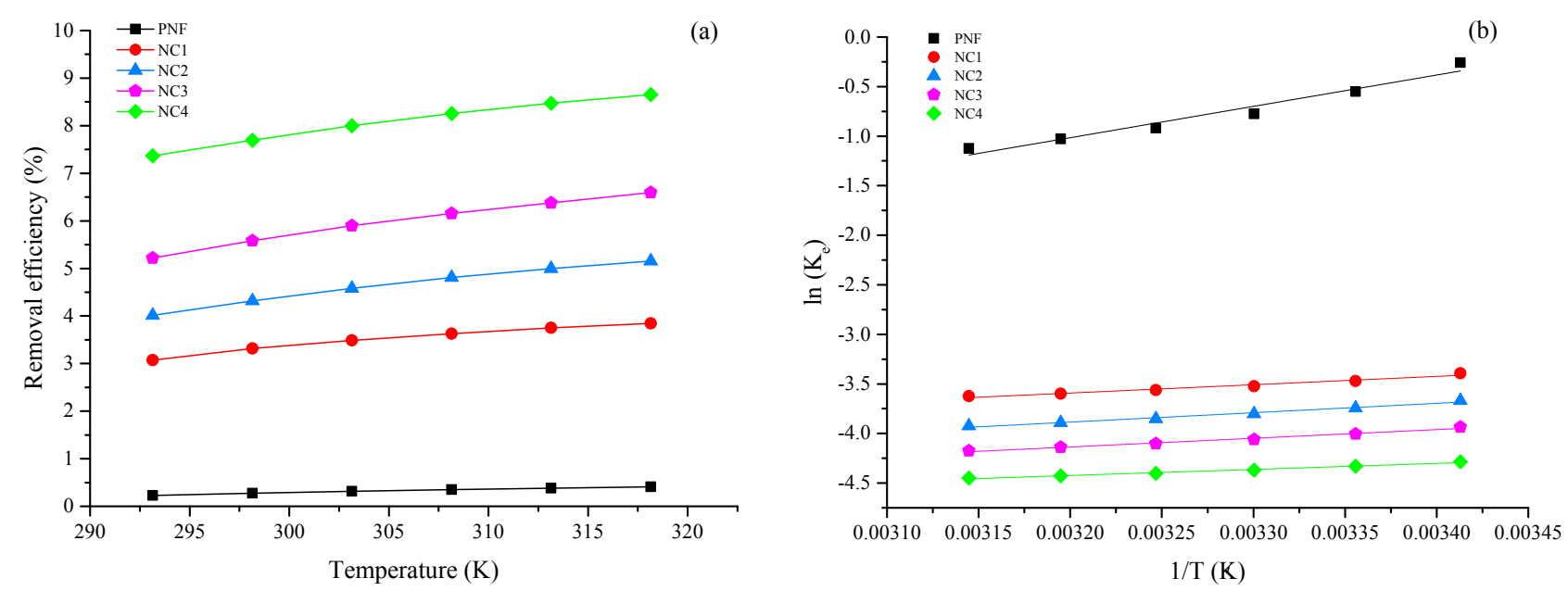

Figure 6. (a) Effect of different temperatures on $\mathrm{Pb}$ (II) adsorption (b) Van’t Hoff plot. 
Table 4. Thermodynamics parameters.

\begin{tabular}{|c|c|c|c|c|c|c|c|c|}
\hline \multirow{2}{*}{ Adsorbents } & \multicolumn{6}{|c|}{$\begin{array}{l}\Delta \mathrm{G}^{\prime} \\
\left(\mathbf{k J} \cdot \mathbf{m o l}^{-1}\right)\end{array}$} & \multirow{2}{*}{$\begin{array}{l}\Delta \mathrm{S}^{\prime} \\
\left(\mathrm{J} \cdot \mathrm{mol}^{-1} \cdot \mathrm{K}^{-1}\right)\end{array}$} & \multirow{2}{*}{$\begin{array}{l}\Delta \mathbf{H}^{\prime} \\
\left(\mathbf{k J} \cdot \mathbf{m o l}^{-1}\right)\end{array}$} \\
\hline & $293 \mathrm{~K}$ & $298 \mathrm{~K}$ & $303 \mathrm{~K}$ & $308 \mathrm{~K}$ & $313 \mathrm{~K}$ & $318 \mathrm{~K}$ & & \\
\hline PNF & 0.69 & 1.36 & 1.95 & 2.36 & 2.68 & 2.97 & 26.29 & 0.09 \\
\hline NC 1 & -8.93 & -9.27 & -9.58 & -9.87 & -10.16 & -10.37 & 7.88 & 0.06 \\
\hline NC 2 & -8.26 & -8.60 & -8.87 & -9.12 & -9.36 & -9.58 & 6.99 & 0.05 \\
\hline NC 3 & -9.59 & -9.92 & -10.23 & -10.51 & -10.77 & -11.04 & 7.28 & 0.06 \\
\hline NC 4 & -10.44 & -10.73 & -11.01 & -11.27 & -11.52 & -11.76 & 5.06 & 0.05 \\
\hline
\end{tabular}

that the adsorption of $\mathrm{Pb}$ (II) is more feasible at higher temperatures owing to the affinity of adsorbents towards $\mathrm{Pb}$ (II) $[53,64]$. The $\Delta \mathrm{G}^{\prime}$ values for pristine PNF, NC1, NC2, NC3, and $\mathrm{NC} 4$ are less than $8.0 \mathrm{~kJ} / \mathrm{mol}$, which confirms that the adsorption of $\mathrm{Pb}$ (II) on all adsorbents are physical adsorption (physisorption) [65, 66]. In the case of $\Delta S^{\prime}$, the obtained values were positive, which showed that the process was irreversible, had an affinity towards $\mathrm{Pb}$ (II) ions, and increased the degree of freedom at the adsorbent/solution interface [67]. The positive values of $\Delta \mathrm{H}^{\prime}$ revealed that the adsorption process was endothermic [68].

\section{Conclusion}

Electrospun PAN nanofibers-based nanocomposites incorporated with fly ash and bentonite were developed at optimized process parameters to produce fine beadles' nanocomposites. The optimization of process parameters was based on the nanofiber's diameter. The optimized diameter of $110 \mathrm{~nm}$ was achieved at $30 \mathrm{kV}$ of potential difference and $200 \mathrm{~mm}$ wire to collector distance. This optimization ensures the maximum exposure of nanocomposite with the $\mathrm{Pb}$ (II) ions. The batch adsorption studies showed that the removal of $\mathrm{Pb}$ (II) can be considerably affected by different factors. $\mathrm{s}$

Moreover, the nanocomposite having the highest amount of fly ash exhibited the highest $\mathrm{Pb}(\mathrm{II})$ removal capacity compared with its counterparts. The equilibrium adsorption data was well explained by the pseudo-second order kinetic model, and the mechanism of adsorption was defined by Bangham's model and the intra-particle diffusion model. The thermodynamic parameters indicated that the adsorption was endothermic and spontaneous. Based on the current study, the developed adsorbent can effectively treat domestic and industrial wastewater for $\mathrm{Pb}(\mathrm{II})$ adsorption. However, further studies are required to check the efficiency against other heavy metl.

\section{References}

1. Zhu F, Zheng YM, Zhang BG, Dai YR. A critical review on the electrospun nanofibrous membranes for the adsorption of heavy metals in water treatment. Journal of Hazardous Materials 2021; 401: 123608. doi: 10.1016/j.jhazmat.2020.123608

2. Yahya MD, Obayomi KS, Abdulkadir MB, Iyaka YA, Olugbenga AG. Characterization of cobalt ferrite-supported activated carbon for removal of chromium and lead ions from tannery wastewater via adsorption equilibrium. Water Science and Engineering 2020; 13 (3): 202-213. doi: 10.1016/j.wse.2020.09.007

3. Hoang MT, Pham TD, Nguyen VT, Nguyen MK, Pham TT et al. Removal and recovery of lead from wastewater using an integrated system of adsorption and crystallization. Journal of Cleaner Production 2019; 213: 1204-1216. doi: 10.1016/j.jclepro.2018.12.275

4. Rashid J, Azam R, Kumar R, Ahmad M, Rehman A et al. Sulfonated polyether sulfone reinforced multiwall carbon nanotubes composite for the removal of lead in wastewater. Applied Nanoscience 2019; 9 (8): 1695-1705. doi: 10.1007/s13204-019-00953-2

5. Chitpong N, Husson SM. High-capacity, nanofiber-based ion-exchange membranes for the selective recovery of heavy metals from impaired waters. Separation and Purification Technology 2017; 179: 94-103. doi: 10.1016/j.seppur.2017.02.009

6. Huang Z, Chen Q, Yao Y, Li X, Lu J et al. Comparison of heavy metal removals from aqueous solutions by chemical precipitation and characteristics of precipitates. Journal of Water Process Engineering 2018; 26: 289-300. doi: 10.1016/j.jwpe.2018.11.003

7. Tang X, Zheng H, Teng H, Sun Y, Guo J et al. Chemical coagulation process for the removal of heavy metals from water: a review. Desalination and Water Treatment 2016; 57 (4): 1733-1748. doi: 10.1080/19443994.2014.977959 


\section{MAHMOOD et al. / Turk J Chem}

8. Hou T, Du H, Yang Z, Tian Z, Shen S et al. Flocculation of different types of combined contaminants of antibiotics and heavy metals by thermo-responsive flocculants with various architectures. Separation and Purification Technology 2019; 223: 123-132. doi: 10.1016/j. seppur.2019.04.068

9. Sunil K, Karunakaran G, Yadav S, Padaki M, Zadorozhnyy V et al. Al-Ti2O6 a mixed metal oxide based composite membrane: A unique membrane for removal of heavy metals. Chemical Engineering Journal 2018; 353: 678-684. doi: 10.1016/j.cej.2018.05.017

10. Ahmadijokani F, Mohammadkhani R, Ahmadipouya S, Shokrgozar A, Rezakazemi M et al. Superior chemical stability of UiO-66 metalorganic frameworks (MOFs) for selective dye adsorption. Chemical Engineering Journal 2020; 399: 125346. doi: 10.1016/j.cej.2020.125346

11. El-Naggar ME, Radwan EK, El-Wakeel ST, Kafafy H, Gad-Allah TA et al. Synthesis, characterization and adsorption properties of microcrystalline cellulose based nanogel for dyes and heavy metals removal. International Journal of Biological Macromolecules 2018; 113: 248-258. doi: 10.1016/j.ijbiomac.2018.02.126

12. Burakov AE, GaluninaIrin EV, Burakova IV, Kucherova AE, Agarwal S et al. Adsorption of heavy metals on conventional and nanostructured materials for wastewater treatment purposes: A review. Ecotoxicology and Environmental Safety 2017; 148: 702-712. doi: 10.1016/j.ecoenv.2017.11.034

13. Jiang D, Yang Y, Huang C, Huang M, Chen J et al. Removal of the heavy metal ion nickel (II) via an adsorption method using flower globular magnesium hydroxide. Journal of Hazardous Materials 2019; 373: 131-140. doi: 10.1016/j.jhazmat.2019.01.096

14. Chong WC, Choo YL, Koo CH, Pang YL, Lai SO. Adsorptive membranes for heavy metal removal - A mini review. In AIP Conference Proceedings 2157. AIP Publishing LLC; 2019. pp. 020005.

15. Brandes R, Brouillette F, Chabot B. Phosphorylated cellulose/electrospun chitosan nanofibers media for removal of heavy metals from aqueous solutions. Journal of Applied Polymer Science 2020; 138 (11): 5002. doi: 10.1002/app.50021

16. Lai KC, Lee LY, Hiew BYZ, Thangalazhy-Gopakumar S, Gan S. Facile synthesis of xanthan biopolymer integrated 3D hierarchical graphene oxide/titanium dioxide composite for adsorptive lead removal in wastewater. Bioresource Technology 2020; 309: 123296. doi: 10.1016/j. biortech.2020.123296

17. Gebru KA, Das C. Removal of $\mathrm{Pb}$ (II) and $\mathrm{Cu}$ (II) ions from wastewater using composite electrospun cellulose acetate/titanium oxide (TiO2) adsorbent. Journal of Water Process Engineering 2017; 16: 1-13. doi: 10.1016/J.JWPE.2016.11.008

18. Li Y, Zhao R, Chao S, Sun B, Wang C, Li X. Polydopamine coating assisted synthesis of $\mathrm{MnO}_{2}$ loaded inorganic/organic composite electrospun fiber adsorbent for efficient removal of $\mathrm{Pb}^{2+}$ from water. Chemical Engineering Journal 2018; 344: 277-289. doi: 10.1016/J. CEJ.2018.03.044

19. Quinn JA, Yang Y, Buffington AN, Romero FN, Green MD. Preparation and characterization of crosslinked electrospun poly(vinyl alcohol) nanofibrous membranes. Polymer 2018; 134: 275-281. doi: 10.1016/j.polymer.2017.11.023

20. Zhu Z, Wu P, Liu G, He X, Qi B et al. Ultrahigh adsorption capacity of anionic dyes with sharp selectivity through the cationic charged hybrid nanofibrous membranes. Chemical Engineering Journal 2017; 313: 957-966. doi: 10.1016/j.cej.2016.10.145

21. Yuan S, Li X, Zhu J, Zhang G, Van Puyvelde P et al. Covalent organic frameworks for membrane separation. Chemical Society Reviews 2019; 48 (10): 2665-2681. doi: 10.1039/c8cs00919h

22. Abdel-Karim A, El-Naggar ME, Radwan EK, Mohamed IM, Azaam M et al. High-performance mixed-matrix membranes enabled by organically/inorganic modified montmorillonite for the treatment of hazardous textile wastewater. Chemical Engineering Journal 2021; 405: 126964. doi: 10.1016/j.cej.2020.126964

23. Irandoost M, Pezeshki-Modaress M, Javanbakht V. Removal of lead from aqueous solution with nanofibrous nanocomposite of polycaprolactone adsorbent modified by nanoclay and nanozeolite. Journal of Water Process Engineering 2019; 32: 100981. doi: 10.1016/j. jwpe.2019.100981

24. Thamer BM, Aldalbahi A, Moydeen M, Al-Enizi AM, El-Hamshary H et al. Fabrication of functionalized electrospun carbon nanofibers for enhancing lead-ion adsorption from aqueous solutions. Scientific Reports 2019; 9 (1): 1-15. doi: 10.1038/s41598-019-55679-6

25. Bode-Aluko CA, Pereao O, Ndayambaje G, Petrik L. Adsorption of toxic metals on modified polyacrylonitrile nanofibres: A Review. Water, Air \& Soil Pollution 2017; 228 (1): 1-11. doi: 10.1007/s11270-016-3222-3

26. Bansal P, Purwar R. Polyacrylonitrile/clay nanofibrous nanocomposites for efficient adsorption of Cr (VI) ions. Journal of Polymer Research 2021; 28 (1): 3. doi: 10.1007/s10965-020-02362-4

27. Mohammadi SZ, Darijani Z, Karimi MA. The synthesis of magnetic activated carbon/cobalt nanocomposite for fast removal of Cr(VI) from wastewater: kinetics, thermodynamics, and adsorption equilibrium studies. Russian Journal of Physical Chemistry A 2021; 95 (S1): S33-S43. doi: 10.1134/s0036024421140144

28. Cui L, Wang Y, Gao L, Hu L, Yan L et al. EDTA functionalized magnetic graphene oxide for removal of $\mathrm{Pb}$ (II), $\mathrm{Hg}(\mathrm{II})$ and $\mathrm{Cu}(\mathrm{II}) \mathrm{in}$ water treatment: Adsorption mechanism and separation property. Chemical Engineering Journal 2015; 281: 1-10. doi: 10.1016/j.cej.2015.06.043 
29. Anastopoulos I, Kyzas GZ. Are the thermodynamic parameters correctly estimated in liquid-phase adsorption phenomena? Journal of Molecular Liquids 2016; 218: 174-185. doi: 10.1016/j.molliq.2016.02.059

30. Lima EC, Hosseini-Bandegharaei A, Moreno-Piraján LC, Anastopoulos I. A critical review of the estimation of the thermodynamic parameters on adsorption equilibria. Wrong use of equilibrium constant in the Van't Hoof equation for calculation of thermodynamic parameters of adsorption. Journal of Molecular Liquids 2019; 273: 425-434. doi: 10.1016/j.molliq.2018.10.048

31. Sen Gupta S, Bhattacharyya KG. Kinetics of adsorption of metal ions on inorganic materials: A review. Advances in Colloid and Interface Science 2011; 162 (1-2): 39-58. doi: 10.1016/j.cis.2010.12.004

32. Awad AM, Shaikh SMR, Jalab R, Gulied MH, Nasser MS et al. Adsorption of organic pollutants by natural and modified clays: A comprehensive review. Separation and Purification Technology, vol. 228. Elsevier B.V., Dec. 01, 2019, doi: 10.1016/j.seppur.2019.115719

33. Wang J, Guo X. Adsorption kinetic models: Physical meanings, applications, and solving methods. Journal of Hazardous Materials 2020; 390: 122156. doi: 10.1016/j.jhazmat.2020.122156

34. Chen S, Qin C, Wang T, Chen F, Li X et al. Study on the adsorption of dyestuffs with different properties by sludge-rice husk biochar: Adsorption capacity, isotherm, kinetics, thermodynamics and mechanism. Journal of Molecular Liquids 2019; 285: 62-74. doi: 10.1016/j. molliq.2019.04.035

35. He Y, Zhang L, An X, Wan G, Zhu W et al. Enhanced fluoride removal from water by rare earth (La and Ce) modified alumina: Adsorption isotherms, kinetics, thermodynamics and mechanism. Science Total Environment 2019; 688: 184-198. doi: 10.1016/j.scitotenv.2019.06.175

36. Chen L, Zuo L, Jiang Z, Jiang S, Liu K et al. Mechanisms of shale gas adsorption: Evidence from thermodynamics and kinetics study of methane adsorption on shale. Chemical Engineering Journal 2019; 361: 559-570. doi: 10.1016/j.cej.2018.11.185

37. Sigwadi R, Dhlamini MS, Mokrani T, Nemavhola F. Structural morphology and electronic conductivity of blended Nafion ${ }^{\bullet}$ polyacrylonitrile/zirconium phosphate nanofibres. International Journal of Mechanical and Materials Engineering 2019; 14 (1): 1-10. doi: 10.1186/S40712-019-0098-1

38. Mohamed A, Yousef S, Abdelnaby MA, Osman TA, Hamawandi B et al. Photocatalytic degradation of organic dyes and enhanced mechanical properties of PAN/CNTs composite nanofibers. Separation and Purification Technology 2017; 182: 219-223. doi: 10.1016/j. seppur.2017.03.051

39. Aqeel SM, Huang Z, Walton J, Baker C, Falkner D et al. Polyvinylidene fluoride (PVDF)/polyacrylonitrile (PAN)/carbon nanotube nanocomposites for energy storage and conversion. Advanced Composites and Hybrid Materials 2018; 1 (1): 185-192. doi: 10.1007/ s42114-017-0002-5

40. Karbownik I, Rac-Rumijowska O, Fiedot-Toboła M, Rybicki T, Teterycz H. The preparation and characterization of polyacrylonitrilepolyaniline (PAN/PANI) fibers. Materials 2019; 12 (4): 664. doi: 10.3390/ma12040664

41. Karacan I, Erdogan G. The influence of thermal stabilization stage on the molecular structure of polyacrylonitrile fibers prior to the carbonization stage. Fibers and Polymer 2012; 13 (3): 295-302. doi: 10.1007/S12221-012-0295-5

42. Zhang SF, Zhao DY, Hou C. Strengthening of polyacrylonitrile (PAN) fiber networks with polyamide epichlorohydrin (PAE) resin. Polymer Bulletin 2018; 75 (12): 5373-5386. doi: 10.1007/s00289-018-2334-X

43. Youssef AM, Al-Awadhi MM, Akl MA. Solid phase extraction and spectrophotometric determination of methylene blue in environmental samples using bentonite and acid activated bentonite from Egypt. Journal of Analytical \& Bioanalytical Techniques 2014; 5 (1): 1-8. doi: $10.4172 / 2155-9872.1000179$

44. Madejová J. FTIR techniques in clay mineral studies. Vibrational Spectroscopy 2003; 31 (1): 1-10. doi: 10.1016/S0924-2031(02)00065-6

45. Chaúque EFC, Dlamini LN, Adelodun AA, Greyling CJ, Ngila JC. Electrospun polyacrylonitrile nanofibers functionalized with EDTA for adsorption of ionic dyes. Physics and Chemistry of the Earth, Parts A/B/C 2017; 100: 201-211. doi: 10.1016/J.PCE.2016.10.008

46. Efome JE, Rana D, Matsuura T, Lan CQ. Metal-organic frameworks supported on nanofibers to remove heavy metals. Journal of Materials Chemistry A 2018; 6 (10): 4550-4555. doi: 10.1039/C7TA10428F

47. Nur-E-Alam M, Abu Sayid Mia M, Ahmad F, Mafizur Rahman M. Adsorption of chromium (Cr) from tannery wastewater using low-cost spent tea leaves adsorbent. Applied Water Science 2018; 8 (5): 129. doi: 10.1007/s13201-018-0774-y

48. Raghav S, Kumar D. Adsorption equilibrium, kinetics, and thermodynamic studies of fluoride adsorbed by tetrametallic oxide adsorbent. Journal of Chemical Engineering Data 2018; 63 (5): 1682-1697. doi: 10.1021/acs.jced.8b00024

49. Foroutan R, Oujifard A, Papari F, Esmaeili H. Calcined Umbonium vestiarium snail shell as an efficient adsorbent for treatment of wastewater containing Co (II). Biotech. 2019; 9 (3): 78. 123AD, doi: 10.1007/s13205-019-1575-1

50. Tohdee K, Kaewsichan L, Asadullah. Enhancement of adsorption efficiency of heavy metal Cu(II) and Zn(II) onto cationic surfactant modified bentonite. Journal of Environmental Chemical Engineering 2018; 6 (2): 2821-2828. doi: 10.1016/j.jece.2018.04.030 
51. Shahzad A, Miran W, Rasol K, Nawaz M, Jang J et al. Heavy metals removal by EDTA-functionalized chitosan graphene oxide nanocomposites. RSC Advances 2017; 7 (16): 9764-9771. doi: 10.1039/c6ra28406j

52. Chen Q, Zheng J, Wen L, Yang C, Zhang L. A multi-functional-group modified cellulose for enhanced heavy metal cadmium adsorption: Performance and quantum chemical mechanism. Chemosphere 2019; 224: 509-518. doi: 10.1016/j.chemosphere.2019.02.138

53. Niu M, Li G, Cao L, Wang X, Wang W. Preparation of sulphate aluminate cement amended bentonite and its use in heavy metal adsorption. Journal of Cleaner Production 2020; 256: doi: 10.1016/j.jclepro.2020.120700

54. Hosseini J, Zare EN, Ajloo D. Experimental and theoretical calculation investigation on effective adsorption of lead(II) onto poly(anilineco-pyrrole) nanospheres. Journal of Molecular Liquids 2019; 296: 111789. doi: 10.1016/j.molliq.2019.111789

55. Zambrano-Intriago LA, Gorozabel-Mendoza ML, Córdova Mosquera A, Delgado-Demera MH, Duarte MMMB et al. Kinetics, equilibrium, and thermodynamics of the blue 19 dye adsorption process using residual biomass attained from rice cultivation. Biomass Conversion and Biorefinery 2020; 1-13. doi: 10.1007/s13399-020-00944-2

56. Wang S, Ning H, NingHu, Huang K, Weng S et al. Preparation and characterization of graphene oxide/silk fibroin hybrid aerogel for dye and heavy metal adsorption. Composites Part B Engineering 2019; 163: 716-722. doi: 10.1016/j.compositesb.2018.12.140

57. Ahmed SM, Taha MR, Taha OME et al. Kinetics and isotherms of dichlorodiphenyltrichloroethane (DDT) adsorption using soil-zeolite mixture. Nanotechnology for Environmental Engineering 2018; 3 (1): 4. doi: 10.1007/s41204-017-0033-8

58. Zou C, Jiang W, Liang J, Sun X, Guan Y. Removal of $\mathrm{Pb}(\mathrm{II})$ from aqueous solutions by adsorption on magnetic bentonite. Environmental Science and Pollution Research 2019; 26 (2): 1315-1322. doi: 10.1007/s11356-018-3652-0

59. Huang X, Zhao H, Hu X, Liu F, Wang L et al. Optimization of preparation technology for modified coal fly ash and its adsorption properties for $\mathrm{Cd}^{2+}$. Journal of Hazardous Materials 2020; 392: 122461. doi: 10.1016/j.jhazmat.2020.122461

60. Ji C, Wu D, Lu J, Shan C, Ren Y et al. Temperature regulated adsorption and desorption of heavy metals to A-MIL-121: Mechanisms and the role of exchangeable protons. Water Research 2021; 189: 116599. doi: 10.1016/j.watres.2020.116599

61. Jiang C, Wang X, Wang G, Hao C, Li X et al. Adsorption performance of a polysaccharide composite hydrogel based on crosslinked glucan/chitosan for heavy metal ions. Composites Part B Engineering 2019; 169: 45-54. doi: 10.1016/j.compositesb.2019.03.082

62. Betiha MA, Moustafa YM, Mansour AS, Rafik E, El-Shahat MF. Nontoxic polyvinylpyrrolidone-propylmethacrylate-silica nanocomposite for efficient adsorption of lead, copper, and nickel cations from contaminated wastewater. Journal of Molecular Liquids 2020; 314 : 113656. doi: 10.1016/j.molliq.2020.113656

63. Manyangadze M, Chikuruwo NMH, Narsaiah B, Chakra CS, Charis G et al. Adsorption of lead ions from wastewater using nano silica spheres synthesized on calcium carbonate templates, Heliyon 2020; 6 (11): e05309. doi: 10.1016/j.heliyon.2020.e05309

64. Chowdhury S, Mishra R, Saha P, Kushwaha P. Adsorption thermodynamics, kinetics and isosteric heat of adsorption of malachite green onto chemically modified rice husk. Desalination 2011; 265 (1-3): 159-168. doi: 10.1016/j.desal.2010.07.047

65. Karmacharya MS, Gupta VK, Tyagi I, Agarwal S, Jha VK. Removal of As(III) and As(V) using rubber tire derived activated carbon modified with alumina composite. Journal of Molecular Liquids 2016; 216: 836-844. doi: 10.1016/j.molliq.2016.02.025

66. Agarwal S, Rani A. Adsorption of resorcinol from aqueous solution onto CTAB/ $\mathrm{NaOH} /$ flyash composites: Equilibrium, kinetics and thermodynamics. Journal of Environmental Chemical Engineering 2017; 5 (1): 526-538. doi: 10.1016/j.jece.2016.11.035

67. Bai C, Wang L, Zhu Z. Adsorption of $\mathrm{Cr}(\mathrm{III})$ and $\mathrm{Pb}(\mathrm{II})$ by graphene oxide/alginate hydrogel membrane: Characterization, adsorption kinetics, isotherm and thermodynamics studies. International Journal of Biological Macromolecules 2020; 147: 898-910. doi: 10.1016/j. ijbiomac.2019.09.249

68. Igberase E, Ofomaja A, Osifo PO. Enhanced heavy metal ions adsorption by 4-aminobenzoic acid grafted on chitosan/epichlorohydrin composite: Kinetics, isotherms, thermodynamics and desorption studies. International Journal of Biological Macromolecules 2019; 123: 664-676. doi: 10.1016/j.ijbiomac.2018.11.082 